\title{
FREDERIC-BACK PARK, MONTREAL, CANADA: HOW 40 MILLION TONNES OF SOLID WASTE SUPPORT A PUBLIC PARK
}

\author{
Martin Héroux ${ }^{1, *}$ and Diane Martin ${ }^{2}$ \\ ${ }^{1}$ Department of Environment, City of Montreal, 1555, Carrie-Derick St., Montreal, Canada \\ ${ }^{2}$ Department of Parks, City of Montreal, 801 Brennan St., Duke Pavillion, 4th flour, Montreal, Canada
}

Article Info:

Received:

27 January 2020

Revised:

26 March 2020

Accepted:

10 April 2020

Available online:

23 July 2020

Keywords:

Landfill site

Landfill gas

Final cover

Public park

Rehabilitation

Recreational activities

\begin{abstract}
The City of Montreal, Quebec, Canada, took over the management, in 1988, of a former limestone quarry that was also used as landfill site. The surrounding population of this site, located in a densely populated area, was exposed to many nuisances related to the rock extraction and transformation and to the landfilling activities. So, the main goal of the city was to rehabilitate this degraded site, build a public park and give it back to the population. The site's total area covers 192 ha. From this surface, 72 ha were devoted to the landfill. Over the years, 40 million tons of municipal solid waste have been landfilled. Building a park on such a large site that still produces landfill gas and leachate involves several major challenges. The priority was first to control, with high efficiency, the landfill gas and the leachate to minimize environmental risks and impacts. In parallel, a process involving design workshops, research, testing, brainstorming and topographical models was launched in order to develop the Master Plan for the park construction. The Master Plan provides the framework for teams working on the project, sets the guidelines for the site's rehabilitation and phase-by-phase transformation based on the principles of sustainable development. The park construction was initiated in the mid nineties. Nowadays, 48 hectares are already open to the population. The Frédéric-Back Park will be finalized around 2026 and will then be completely accessible to the public. This is the result of a close collaboration between the Department of Parks and the Department of Environment of the City of Montreal in order to meet the needs of both past and future functions of this rehabilitated site.
\end{abstract}

\section{INTRODUCTION}

The City of Montreal, Quebec, Canada, has set ecological transition as one of its main priorities. As part of this ambitious process, the Frédéric-Back park (Figure 1) represents a flagship project to demonstrate how this priority can be expressed in a major concrete action. This park is being built on top of the City of Montreal's 40 million tons landfill site. It shows how a highly degraded site can be given back to the population to provide a better life quality.

The park is located on a 192 ha piece of land. According to Ethnoscop (2013), some quarrying limestone activities were initiated on those rural lands during the middle of the 19th century. Because of Montreal expansion, needs in stone blocks, crushed stones, and concrete were increasing. This is why during the fifties, activities were diversified on site by adding a cement kiln and an asphalt plant. So the quarry became a major employer and its neighborhood got developed quickly to provide housing to the workers. With time, the growing city reached this former rural area which is now densely populated with 8700 persons $/ \mathrm{km}^{2}$ (Figure 1).

Landfilling operations were initiated in 1968 by previous owners who were also exploiting the limestone extraction and the related industrial activities. At that time, there was no regulation on landfilling in the Province of Quebec. Therefore the landfill was not initially designed to prevent environmental impacts, risks and nuisances for the surrounding population. For example, walls and bottom of the old quarry were not made water tight before landfilling. So there is a hydraulic link between local aquifers and landfilled waste. As a result, there are potential risks of groundwater contamination by leachate and potential risks of lateral landfill gas (LFG) migration through unsaturated rock fractures and soil porosity.

During the seventies, the already dense population reacted to the many nuisances as odors and vermin from the landfill and asphalt plant, noise and vibrations from rock blasting and the intensive trucking related to rock, crushed stones, asphalt, concrete and waste transportation. The 
complaints and social pressures inherent to those impacts and addressed to local public administration increased to such an extent that the City of Montreal decided to expropriate the company owning the site. Because of the long administrative and legal process, the expropriation became effective in 1988. Quarrying and related industrial activities then stopped but the landfill site kept being operated. Even with 26 million tons of waste already buried, the top of the site was still considerably lower than the natural ground surface which would have made it difficult to control run off water. Even though the site was to become a park, the priority was to minimize environmental risks and impacts and to ensure progressive closure. The following few years focused on this priority.

In parallel the city administration tasked the Service des grands parcs, du Mont-Royal et des sports (Department of Parks) to turn the site into a park and coordinate the work. A major initiative was then launched to determine the best way to proceed, in collaboration with the Service de l'environnement (Department of Environment) and the Ministère de l'environnement et de la lutte contre les changements climatiques (MELCC - Ministry of Environment and the Fight Against Climate Change). The process involved design workshops, research, testing, brainstorming and topographical models in order to develop the Master Plan for the site as a whole, which was adopted in 1997. That Master Plan, which is illustrated in Figure 2, provides the framework for teams working on the project, sets the guidelines for the site's rehabilitation and phase-by-phase transformation based on the principles of sustainable development. It defines the site mission and assigns 153 hectares to a metropolitan park and 39 hectares to businesses, environment-related industries and world-class cultural and sports institutions.

The landfilling was pursued until 2009 over 72 ha area with a depth up to 75 meters. It took five more years to complete the final cover.

Since the beginning of the park construction work, 48 ha have been finalised and open to the public and the rest will be progressively developed. There are a vast number of users that appreciate the vastness, the natural aspect and the biodiversity and fauna already present on site. The construction of the park will be finalized close to 2026 and it will then be completely accessible to the population.

This paper presents the steps of the metamorphosis of the landfill site into Frédéric-Back Park, since its take over by the City of Montreal. It first describes how it was made safe for the surrounding people and for the environment. Then it presents concepts and objectives behind its transformation into a park. It finally exposes the main actions taken to meet the needs of both past and future functions.


FIGURE 1: Frédéric-Back Park location in a densely populated area of Montreal, Province of Quebec, Canada. 


\section{AN ENVIRONMENTAL REHABILITATION}

\subsection{Landfill gas management}

In 1988, the collection system was under designed. It was made of 40 vertical collecting wells and one 5100 $\mathrm{m}^{3} / \mathrm{h}$ centrifugal blower (Héroux and Turcotte, 1997). Moreover those first wells were all located in a small zone which was covering about one fourth of the area devoted to landfilling. Many evidences of LFG atmospheric emissions and lateral migration were showing the inefficiency of the collection system. This is why the City of Montreal has made huge investments and efforts to control LFG. During the next 10 years, the collection system was gradually upgraded to reach 300 vertical wells, five $6800 \mathrm{~m}^{3} / \mathrm{h}$ rotary lobe compressors and close to $20 \mathrm{~km}$ of collector pipes. Wells drilled close to the quarry walls were spaced $40 \mathrm{~m}$ apart to obtain an efficient control of LFG lateral migration while the wells located in the center part were drilled approximately every $60 \mathrm{~m}$. Based on the results of an extensive environmental monitoring program (this program is described by Héroux, 2000) and the measured performance of the existing wells, 85 additional gas wells were added to the collection system from 1998 to 2007.

In order to estimate the efficiency of the gas collection system and make appropriate decisions regarding how it should evolve and how it should be operated, many research projects were carried on over the years:

- LFG surficial emissions (Héroux et al., 2010, Fecil et al., 2003);

- LFG generation and flow (Lagos et al., 2017, Héroux, 2008, Nastev, 1998);

- Methane biological oxidation (Héroux, 2008);
LFG lateral migration (Franzidis et al., 2008, Nastev et al., 2003);

Optimization of LFG collection (Héroux, 2008).

Those studies provide valuable measured data that permits to estimate a LFG collection efficiency reaching $95 \%$, using a mass balance. This mass balance takes into consideration gas collected, surface emissions, biological oxidation, and lateral migration. This $95 \%$ efficiency is in the high end of what is reported in literature. For example, many authors report efficiencies that can reach $90 \%$ (Wang et al., 2020, Sun et al,. 2019, De la Cruz et al., 2016). Some others report that it can reach close to 100\% (Ayodele et al., 2020, Lee et al., 2017, Spokas et al., 2006), depending of the phase of the landfill, the type of final cover and the extension of the gas collection system. Montreal site is in the aftercare phase, it has an extensive LFG collection system with a high density of wells, and its gas impervious final cover is completed. In this context, the estimated $95 \%$ LFG collection efficiency, based on data gathered on field studies, is consistent with efficiencies reported in the literature.

It was also possible to evaluate that a minimum of 150 wells would be required to keep this efficiency in the long run. Those projects have also motivated and contributed to the design of a 820-metre-long soil ventilation trench, built in 2006 and 2007 in the overburden along the north side of the landfill site. This trench is a LFG lateral migration control infrastructure that is designed to be operated passively or under vacuum.

Since 1996, collected LFG is compressed and burned in a power plant to produce electricity. At first, technology used consisted of a boiler, a steam turbine and an alter-

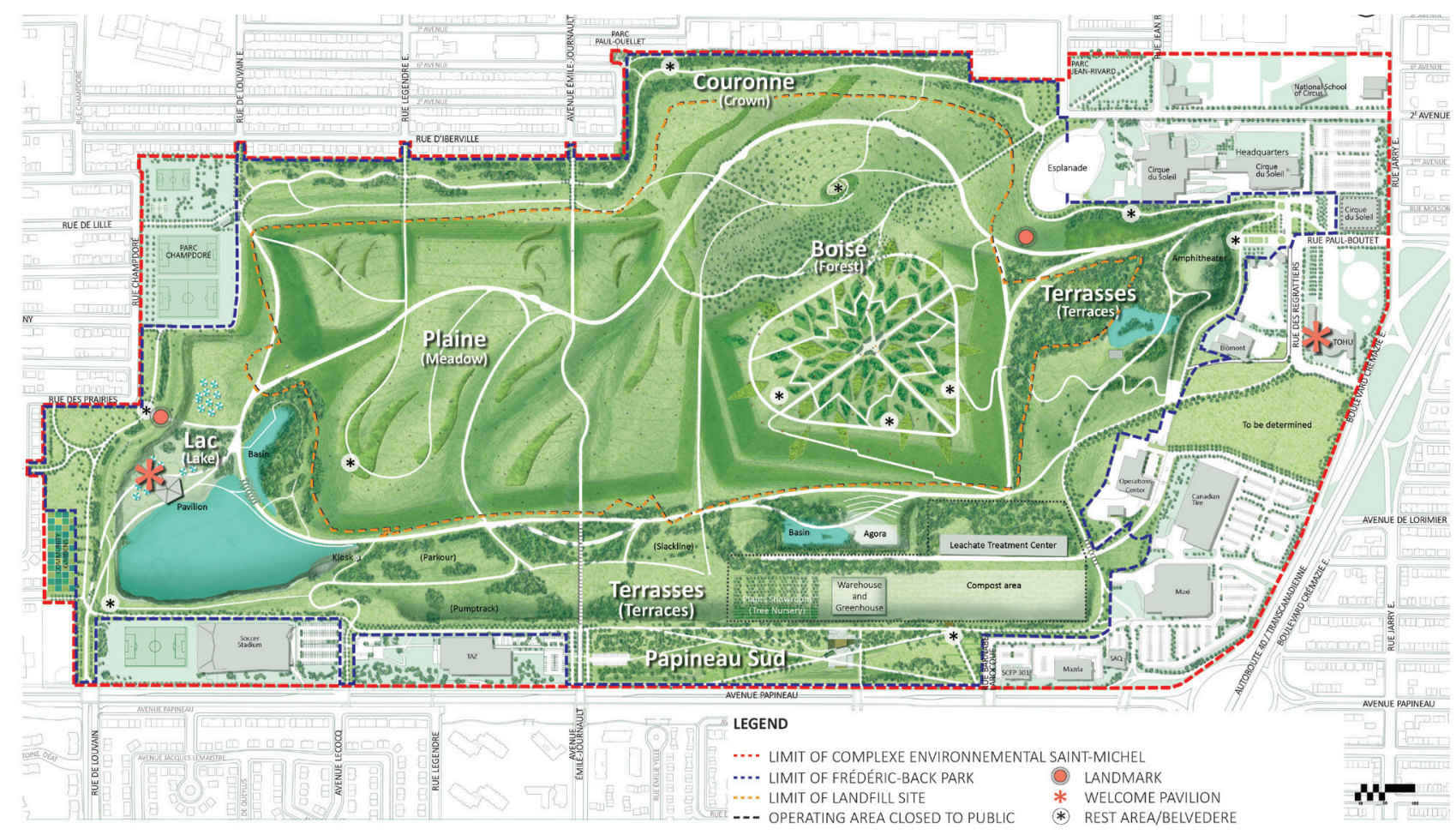

FIGURE 2: Frédéric-Back Park Master Plan. 
nator with a total electrical capacity of $23 \mathrm{MW}$. With the decrease of LFG generation, a technological change was needed so in 2017, three LFG combustion motors were installed to replace the previous technology. Those motors produce up to $4.8 \mathrm{MW}$ of electricity. Residual thermal energy of both technologies has been used since 2005 to heat the TOHU's building and since 2018 the Cirque du Soleil international headquarters, both located very close to the power plant. The TOHU is a non-profit organization that has a double mission: 1. promote circus arts by staging shows in a large circular theatre and 2. provide a welcoming pavilion and animation of the park.

The LFG collection system is planned to be maintained and operated for many decades. This is why it is integrated in the park design.

\subsection{Leachate management}

As mentioned earlier, prior to the beginning of the landfill operations, the bottom and walls were not rendered impervious. Therefore, there is an existing hydraulic link between aquifers and waste materials. The geological formations in and around the sanitary landfill site are of sedimentary rocks composed mainly of calcareous rocks with mostly horizontal layers, which vary from $10 \mathrm{~cm}$ to 100 $\mathrm{cm}$ in thickness. Groundwater moves through a network of cracks. Besides the stratification joints, three main sub vertical diaclases networks have been identified. In this area, groundwater is found at an approximate depth of $5 \mathrm{~m}$ to 10 $\mathrm{m}$ and its flow direction is $\mathrm{N}-\mathrm{E}$, towards Des Prairies River (Bériault and Simard, 1978). Hydraulic conductivity of the rock that was measured close to the site. It varies between $10^{-8} \mathrm{~m} / \mathrm{s}$ and $10^{-5} \mathrm{~m} / \mathrm{s}$ (Héroux and Dubois, 1994).

However, dams and crushed stones drainage canals were built to facilitate the flow of the leachate towards a pumping station made of two wells. The maximum flow of the leachate reaching the pump is approximately 1800 $\mathrm{m}^{3}$ per day. Such a flow allows for the creation of a depression cone the size of which is sufficient to direct the groundwater to the landfill site. That cone of depression makes groundwater flow in the landfill site and prevents groundwater contamination by leachate. The good quality of the groundwater around the site and the direction of the hydraulic gradients demonstrate the efficiency of the leachate control system. Since the groundwater that flows in the waste dilutes leachate, its chemical load is lower than what it is generally observed in landfill sites. However, it is important to note that a substantial part of the waste remains saturated.

When recovered at the pumping station, the leachate is then treated by oxidation to reduce its sulfide content prior to its disposal in the public combined sewers. Since the oxidation chamber was underground built, it is completely hidden from the view of the park users. From there, the treated leachate is sent to the sewer and reached the sewage treatment plant of the Montreal agglomeration. Because of a recent regulation modification, the treatment process must be revised in order to reduce leachate's ammoniacal nitrogen concentration. In this context, a new treatment plant will be in operation within the next two years. The leachate control and treatment are planned to be maintained and operated for many decades. The park is designed consequently so pumping wells and pipes are accessible for operations and maintenance.

\subsection{Final cover}

The design of the final cover was done according to several conception parameters. Its desired functions were prioritized as follows: 1) control of LFG 2) rules and bylaws 3) costs, 4) potential and future utilization, 5) geotechnical requirements, 6) maintenance, 7) control and management of leachate (Tremblay et al., 2001). The global selection process is described in detail by Tremblay and Héroux (1999). The design choices were, among others, based on results obtained on three one ha test plots that were constructed and instrumented to test some final cover concepts under field conditions. Tremblay et al. 2001, present the main results, of those experimentations.

The components of the final cover are the following, from the top to the bottom:

Top soil $(0.15 \mathrm{~m})$ : It is a mix of compost made on site out of leaves collected in the city parks and ramial chipped wood;

- Protection layer $(0.45 \mathrm{~m})$ : It is a coarse excavation material that comes from Montreal's vicinities excavation works. It gives a mechanical protection to the underlying layer;

- Capillary layer $(0.45 \mathrm{~m})$ : This layer is made of silt that comes from Montreal's vicinities excavation works. The capillary barrier effect occurs at the interface between two materials having different textures, permitting the finer layer to remain permanently close to the maximum effective water saturation. In this way the capillary layer is impervious to LFG flow and air infiltration;

- Filtration layer $(0.10 \mathrm{~m})$ : The filtration layer is composed of close grading sand on top of a nonwoven geotextile. The function of this layer is to prevent the loss of the capillary material through the underlying drainage layer; - Drainage layer $(0.3 \mathrm{~m})$ : This layer is made of crushed stone, bricks, concrete and asphalt that are recuperating from road and building renovation or demolition. Its main function is to collect LFG that is not collected by the gas wells.

As it can be noted in the previous description, the only layer of the final cover made out of virgin materials is the filtration layer. All other components are built with recycled materials such as leaves, wood chips, excavation material or crushed construction and demolition waste..One of the main concerns regarding the park construction was to plant some trees on top of the final cover without compromising its capacity to achieve its functions. For example, would the root systems of the trees enter in the capillary layer and drain out the water which would increase its gas permeability? To answer this question, a plantation test was realized. Trees of $50 \mathrm{~mm}$ diameters were planted in 2005. Seven years later a field study of the root system of some of those trees was achieved utilizing a high-pressure air blow gun to remove soils around roots and rootlets without breaking them. Density of the final cover layers was also measured using radiation-type densimeter. Figure 3 shows two pictures of the field work involved in this study. 
The main finding of this field study is that the roots don't penetrate the capillary barrier because its density is too high. This observation is reassuring with respect to maintaining the final cover's integrity and functions. However, as the root system remains shallow (it is confined to the protection layer) trees are more sensitive to high winds and are likely to uproot.

\section{THE PARK'S MASTER PLAN AND ITS CON- STRUCTION}

\subsection{Master Plan - mission \& objectives}

The mission set out in the Master Plan is to create an environmental technology complex around a vast green space, turning the industrial past of the site into an asset and demonstrating the knowledge and skills required to develop and maintain such a project. The objectives are as follows:

Encourage knowledge in environmental rehabilitation by establishing a site dedicated to environmental research, experimentation, innovation and education;

Offer park activities oriented to the environment, sports, recreation and culture;

Enhance the quality of life of Montreal residents in cooperation with the community, institutional and business partners;

Help protect and improve biodiversity in Montréal;

Contribute to the social and economic health of the community around the park.

\subsection{Design concept}

Based on the theme of metamorphosis, the Master Plan focuses on three characteristics of the site: Vastness,



FIGURE 3: Root cleaning with a high-pressure air blow gun (up) and cleaned roots (down) in the protection layer.

Environmental engineering and Unusual experiences. The site is divided into eight sectors, four in the Crown, the upper plateau that forms the site perimeter, and four others in the Centre, the excavated quarry and its natural features (Figure 4).

The Crown, which has been opened to the public since 1995, encompasses the cultural, sports and industrial-com-

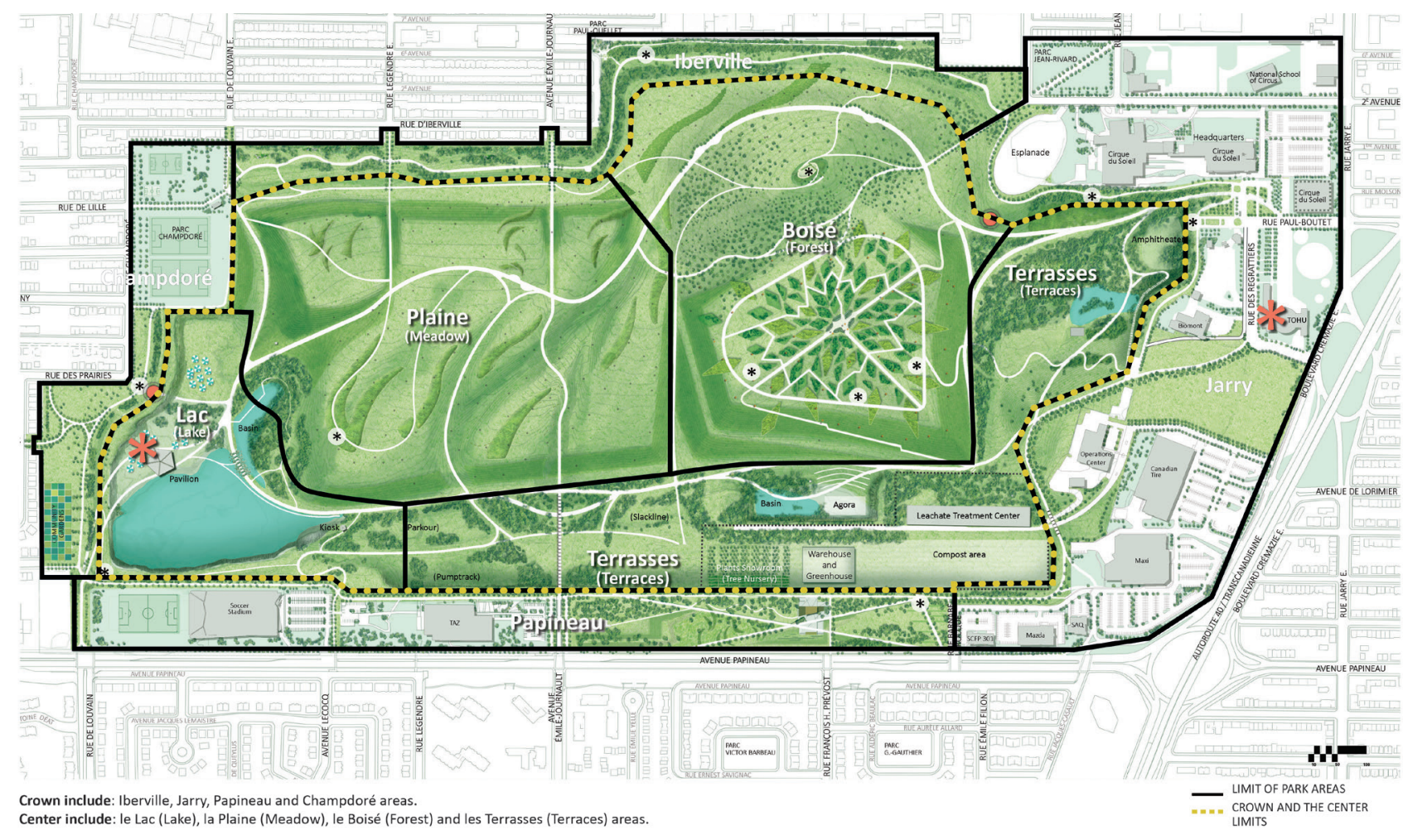

FIGURE 4: The various areas of the park. 
mercial poles, the 17 entrances to the site, the Papineau (Figure 5), Champdoré, Iberville and Jarry sectors, and the 5.5-kilometre multi-use pathway that links them all together. It also includes the welcoming pavilion, businesses, and culture and sports institutions, the Parvis (which showcases the Centre), community gardens, three belvederes and several rest areas. Recent improvements include lighting, parking, washrooms, picnic areas and urban fixtures, as well as planted areas.

The Centre forms the middle of the site. It includes the area that was stripped out during quarry operations, and the landfill site. The Centre is divided into four sectors whose specific aspects, features and design are reminders of the site's past uses: the refreshing lake surrounded by limestone cliffs recalls the quarry; the windy plain, with its hilly slopes and grassy fields, evokes the landfill area; the secluded wooded area marks the current naturalization phase, with artworks dotting trails shaded by groves of trees; and lastly, the terraces connect with the urban context and provide unusual recreational facilities. There is a network of pathways and trails for walking, biking, cross-country skiing and snowshoeing, as well as street furniture, a pavilion for water-based activities, an agora and a natural amphitheatre for scheduled and spontaneous events. There are also picnic areas, naturalized retention basins, site-specific fixtures, and fun sports facilities. All these elements help to enjoy the vastness, unicity and historical nature of the site (Figure 6).

\subsection{Design criteria}

Given that the site's development is taking place in stages over many years, principles were established to guide the designers and ensure a coherent approach between the sectors and within each phase of construction. Four main principles were defined:

Intervene with a sustainable and environmental approach;

- Emphasize the genius loci of the site and its unique nature;

- Offer a site that is welcoming, safe and accessible;

- Encourage research, education, innovation and creativity in site design, activities and management.

More than 50 actions derive from these principles, including the following:

- Ensure ecological management of runoff and storm water, as well as waste materials;

Promote the use of renewable energy;

- Use recycled waste materials to create the park;

- Focus on public transit and active modes of transportation to access the park;

- Create pathways that are inviting and easy to use in every season;

- Create vistas around the park to incite visitors to go towards the centre;

- Showcase the history of the site and offer views of Montreal landmarks;

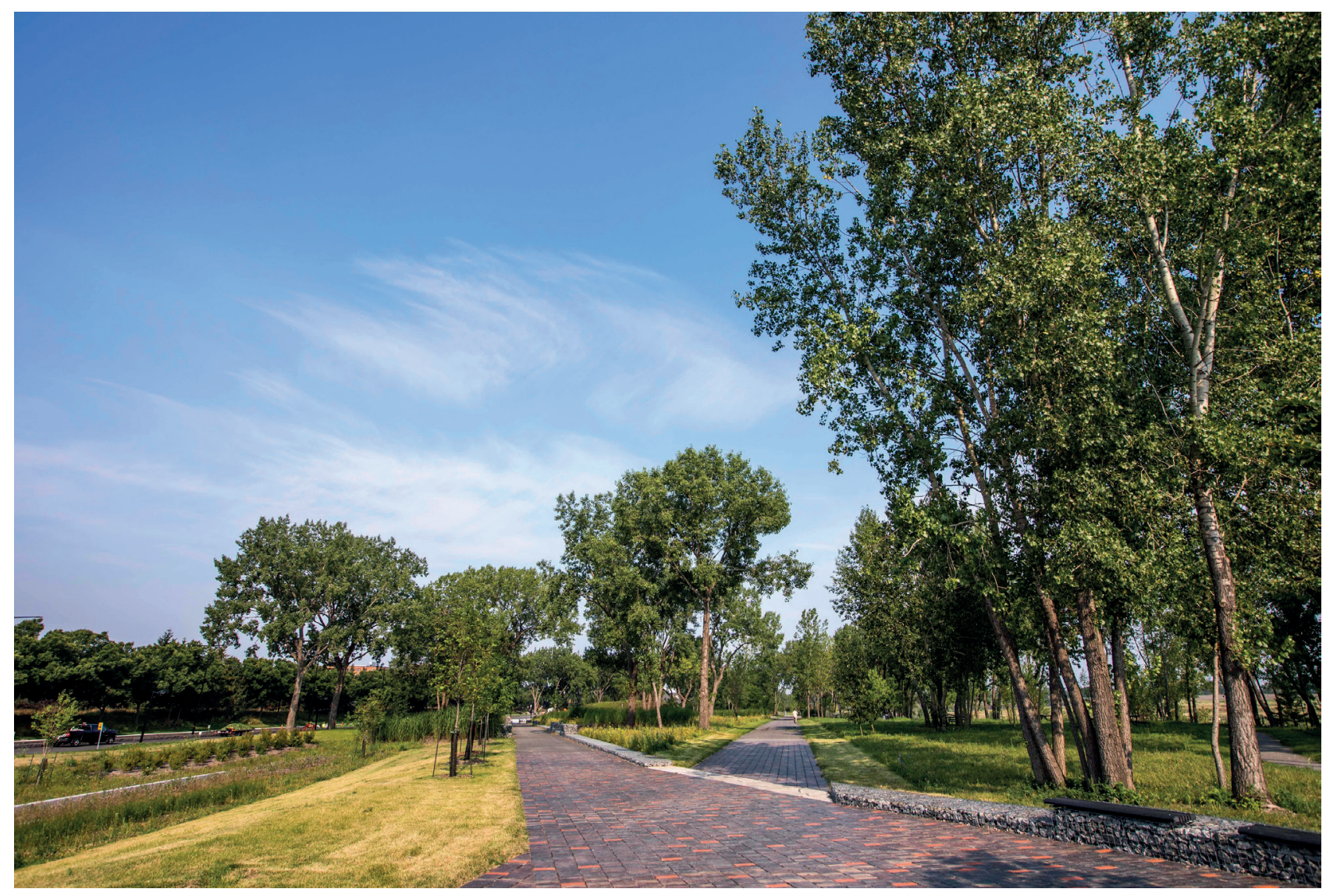

FIGURE 5: The Crown, sector Papineau. 

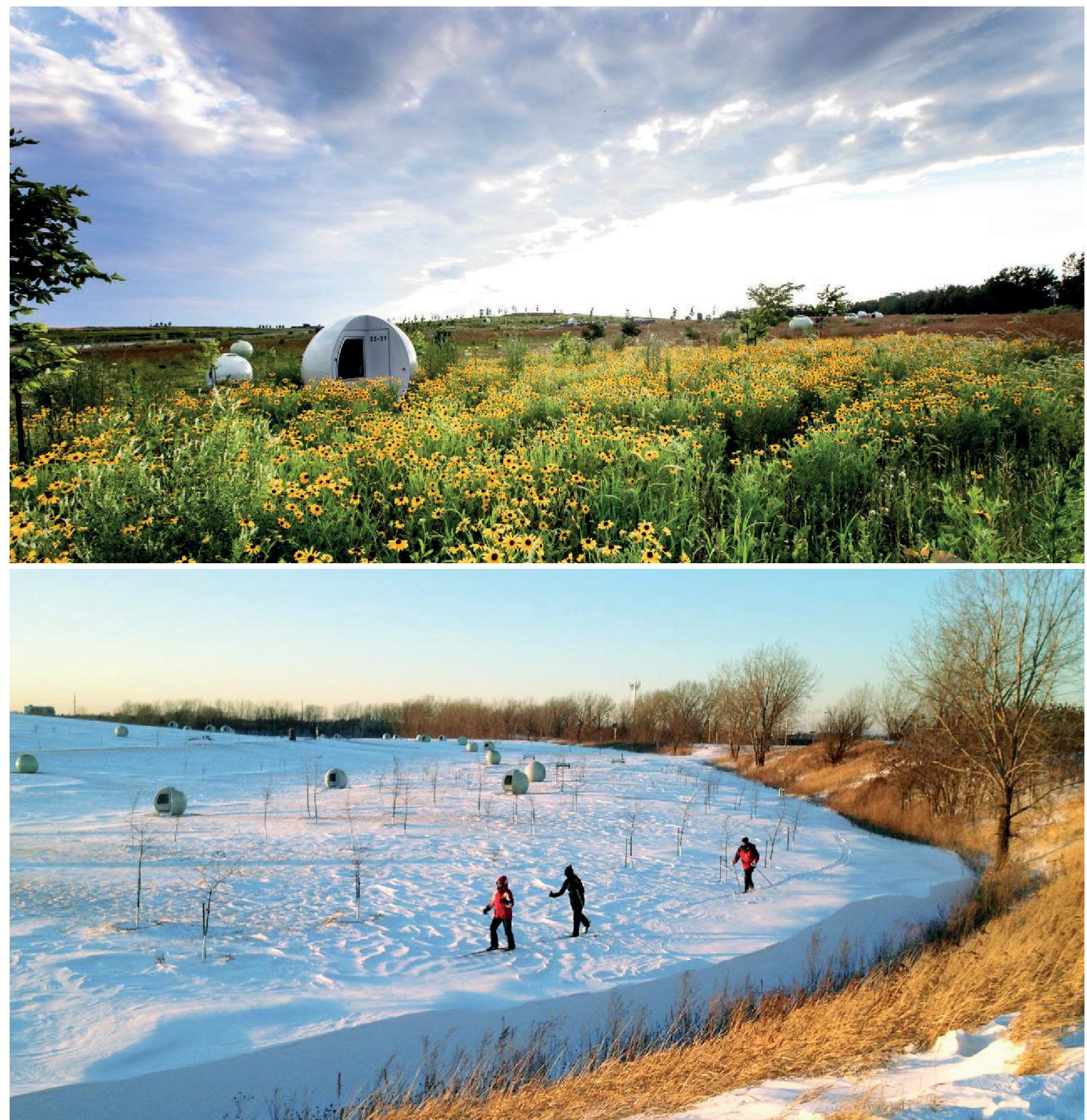

FIGURE 6: The Centre: open section to the public of the secluded wooded area during summer time (up) and winter time (down).

- Encourage research and technological innovation;

- Create facilities that will foster activities in relation to the environment, education, recreation and culture (Figure 7);

- Strengthen visitors' social and environmental awareness.

\subsection{Timeline and costs}

Figure 8 shows the construction sequence of FrédéricBack Park which the main milestones are listed as in Table 1.

The park's construction costs, financed by the Montreal Agglomeration, are estimated at 350M CAD, with $120 \mathrm{M}$
CAD already spent for the previous phases. Other municipal investments of 60M CAD were made for municipal facilities, with another $100 \mathrm{M}$ CAD to come. Meanwhile, the private sector on site has invested 106M CAD in its facilities, with another 150M CAD announced for the next five years.

\section{THE NEEDS OF BOTH PAST AND FUTURE FUNCTIONS}

Transforming Frédéric-Back Park is a complex act that demands a bold, creative and innovative approach. Creating a park on such a large landfill and opening it to the 




FIGURE 7: Various activities organized in the Frédéric-Back Park.

public while the buried waste is still decomposing and releasing LFG and leachate is a highly unusual endeavour. It has taken vision, perseverance, ingenuity and courage to develop this green space, as well as an exceptional collaboration between two municipal departments (parks and environment), with some support from the MELCC, experts from the private sector and specialized contractors.

\subsection{Opportunities and restrictions}

The project offers unique opportunities and interesting reminders of the history of Montréal, including three kilometers of cliffs created by the removal of limestone used to build the city. It also offers spectacular vistas of the downtown area and local landmarks, as well as views overlooking the park. In addition, naturalized retention basins encourage the already astonishing biodiversity on the site, and the environmental monitoring equipment can also be used for educational purposes. Lastly, phase-by-phase implementation has allowed for ongoing feedback and adjustments. Despite the opportunities, the site presents considerable constraints. This is why, significant restrictions must be taken into consideration for the project, amongst them:

Unpredictable soil movements caused by the subsoil; Ensuring careful daily management daily maintenance of the LFG and leachate generated by the decomposing buried waste;
Dry and clayey soil for planting with dry and windy conditions, which limit the type of plants that can be used; - The need to quickly evacuate runoff water away from the landfill area, which affects the vegetation planted there; - The difficulty to ensure security of the lower enclosed site surrounded by over $3 \mathrm{~km}$ of cliffs, with little visibility from the street (Figure 9);

- Limited public transit services and parking spaces in the area.

\subsection{Rules and regulations}

The park construction is regulated by many government levels. Obtaining the required various permits was a complex task.

The MELCC is responsible for regulating sanitary landfill sites operations and closure. It is also responsible for the construction on top of such sites. Moreover it regulates for natural habitats, undesirable plants and plans of water. All construction actions must thus be pre-authorized by this ministry.

The management of wild animals is handled by a provincial law, while the protection of bird species is governed by federal legislation. This has an impact on work timelines, and involves mitigation measures that increase the project's complexity.

Frédéric-Back Park and the landfill are part of Greater Montreal, the 16 boroughs located on the Island of Mon- 


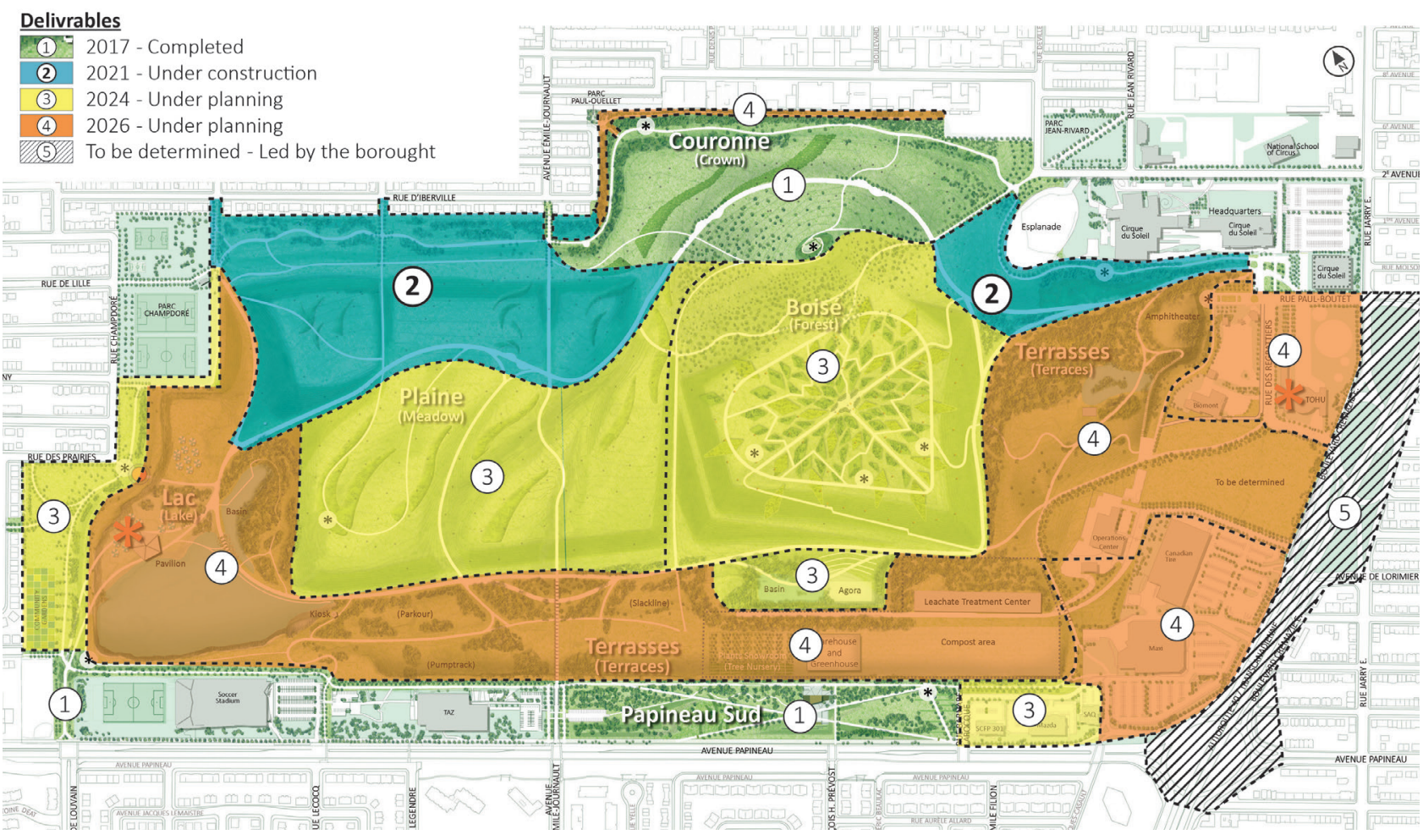

FIGURE 8: Construction sequence of Frédéric-Back Park.

tréal, including the City of Montreal. The funds for managing and developing the site come from this administrative unit, which means that the impact of the park effectively extends beyond the City of Montreal.

Furthermore, the City of Montreal is responsible for various issues that affect the site: sewer discharge quality, air quality, public safety, etc. Activities related to park design and subsoil monitoring require approval from eight different municipal departments (water, environment, public safety, culture, buildings, infrastructures, and boroughs for the urban development plan and permits).

\subsection{Issues Management}

A management strategy has been drawn up to limit the scope of some of the issues identified over the course of the project. The following are six examples of issues and solutions devised to reduce the risk of problems:

- To reduce costs and protect the environment, materials have been recycled for appropriate uses within the park. The storage of such materials is only authorized on $15 \%$ of the park area. Every six months, the planning of stored materials and operations is updated to ensure safe access to the materials without interfering with truck routes on the site;

- The sequence of each phase of work must take into account the safety of both visitors and workers, as well as storage capacity, runoff patterns, improvements to the underground environmental monitoring system, the boundaries of each work site when several contractors are working at the same time on site, etc;

- The sectors opened first for technical reasons allow walking, observation and simple enjoyment, but the demand is high for activities that are presently inappropriate due to the subsoil composition. The animation team offers pleasant activities that do not impact the newly constructed areas while the planning and communication team promotes an interest in the later phases of the park, where more intensive uses will be permitted;

TABLE 1: The main milestones of the design and the construction of Frédéric-Back Park.

\begin{tabular}{|c|c|}
\hline Years & Realizations \\
\hline 1988 & Site management is taken over by the City of Montreal \\
\hline $1988-2014$ & $\begin{array}{l}\text { Consultations and elaboration of the Master Plan adopted in } 1997 \text { / Construction of the Crown ( } 30 \text { ha) and its multi-use linear trail / } \\
\text { Establishment of businesses, industries and institutions on } 45 \% \text { of the perimeter area / Adoption of a sustainable development chart } \\
\text { and design guidelines / Authorization from the provincial ministry to start developing the Centre }\end{array}$ \\
\hline $2015-2017$ & Construction of the park's block 1 ( $19 \mathrm{ha}$ ), including part of the Centre \\
\hline $2018-2021$ & $\begin{array}{l}\text { Construction of the park's block } 2 \text { ( } 24 \text { ha), planned to open in } 2021 \\
\text { Updating of the Master Plan and design guidelines (2020) }\end{array}$ \\
\hline $2022-2026$ & Construction of the park's blocks $3(35 \mathrm{ha})$ and $4(45 \mathrm{Ha})$ \\
\hline
\end{tabular}




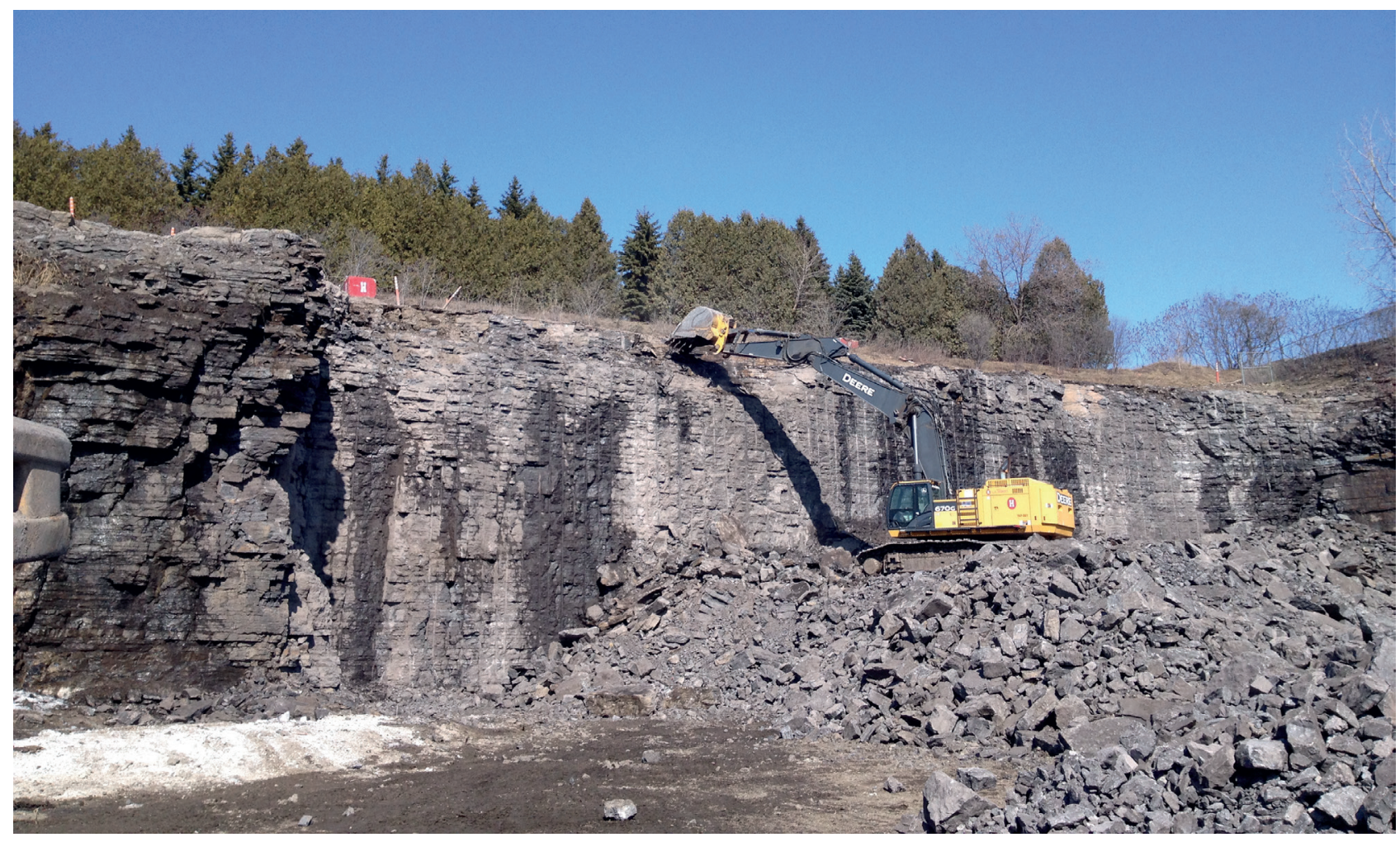

FIGURE 9: Securing the cliffs.

Human-wildlife cohabitation is a goal for the park, but the social acceptability of some animals on the site is a complex issue. To facilitate cohabitation, design planning is done to achieve a balance between the areas opened to humans and the areas assigned to animals. This is complemented by educational and awareness-building activities, along with guided tours by wildlife experts to help visitors understand the role of wildlife in the ecological balance of the park;

- In 2000, a project with local citizens was realized with an international artist: huge circles of flowers were created in the unopened area, symbolizing the pollination of the site. These circles were to stay there for a few years but the following year, a major soil collapse required corrections and the circles had to be eliminated. To avoid deception and frustration amongst participants, the City explained the situation and proposed to donate the flower plants to the local population, asking them to pollinate the whole neighbourhood. Citizens still send us pictures of the donated plants in their backyard;

- The planting conditions in the park are difficult and plants must be young and small to survive and grow in such harsh conditions. At the same time, people want to use the park and do not realize the impact their presence has on plants and seeding. This is why we provide extra attention to the plants in the first 3 to 5 years, like a nursery, by isolating certain planting beds, resowing grasses and ground cover every year, planting more densely at first then transplanting to respect space needed, etc. These actions are time consuming but help citizen appropriation and maintain the interest for the park.

\subsection{Creativity at its best}

The following are some examples of the City's creative response to the site's realities.

\subsubsection{Sustainable actions}

Over the years, many actions were developed to promote sustainable development of the park. Here are some of these:

A sustainable development charter was drafted specifically for the park;

- The fence separating the area open to the public from the closed area under construction is installed over crowd control barriers, which means it can be relocated easily when needed;

Native plants are used to reduce maintenance, watering needs and to foster biodiversity (ex.: planting corridors dedicated to monarch butterflies and pollinating insects, ecological niches for threatened species on the site, etc.);

- The centre of the park is a zero-waste area;

- Park activities are organized with a partner (la TOHU) who has a local hiring policy;

- Two sustainable mobility hubs will be created on the site in 2019 and 2021 to encourage active, environmentally friendly and sustainable trips to the park, and reduce dependence on cars;

Given that leachate and LFG will be produced for sever- 
al more decades, the proposed facilities and equipment are modifiable and evolving to ensure their usefulness throughout that time;

- For each new design phase, presentations and information sessions are organized with elected officials, the general administration and citizens/partners to sustain everyone's interest and involvement in the project;

Since 2005 guided tours of the site are offered to adults, senior citizens, students of all ages, and day camp children to heighten awareness for sustainable and ecological changes in their own life.

\subsubsection{The spheres}

Before opening the central area of the park to the public, the LFG collection wells needed to be protected. This is why the spheres were designed with practical and aesthetic functions in mind.

They first provide an easy access to the LFG collection wells for monitoring and adjustments. The round shape helps the case's integration with the rolling topography. The three windows that allow the passage of air prevent the entry of insects and rodents. The spheres are covered with a phosphorescent film that absorbs UV from the sun during the day and releases it at dusk, echoing the starry skies. At night, a flashlight can be used to 'draw' on the surface without leaving any permanent marks. Some spheres are shown in Figure 10.

\subsubsection{Selective plant material}

A variety of planted landscapes is encountered when travelling through the park; species are determined by the thickness of the planting soil, added on top of the final garbage cover. With rain as the only water source, the selected plants have to be hardy, drought tolerant, and offer seasonal interest. Given the environmental mission of Frédéric-Back park, native Quebec plants that can handle the difficult conditions of the site are preferred to create natural wildlife habitats. They also contribute to reduce urban heat islands. Through these actions, the park helps the City of Montreal to meet its goal of improving biodiversity in its territory.

\subsubsection{On-site material reuse}

In the development of Frédéric-Back Park, major emphasis has been placed on recycling and recovering of old materials. Ultimately, nearly five million tonnes of material will be reused instead of going to landfill or being burned. Here are some examples: The soil used to build the park is a mix created on-site with recycled materials (earth and sand from other construction sites, compost from the fall leaves collected by the city, tree-pruning waste). It is less expensive and more ecological to produce the soil on site than to buy it from soil suppliers.

Before any work can be done near a cliff, and to prevent rock falls, the cliff must be made secure. This operation creates rock debris that is collected and crushed, then reused as a sub foundation and foundation for the park's pathways and roads. Boulders are reused as well to build retaining walls and steps, to create seating along pathways, etc.

Ash trees attacked by the emerald ash borer and cut down by the City of Montreal are retrieved, planked and


FIGURE 10: The spheres are designed to protect the LFG collection wells and make part of the park experience. 
thermo-treated then used to build custom furniture for the park (Figure 11). This wood is also considered to be used in future buildings, signage, activities.

The granite edging and paving stones stored on site for some 15 years are being used to construct irrigation ditchers, to create rest areas and to delimit crossroads in the pathway network.

A small nursery was created on site to receive suitable plants removed from other city parks or surplus plants from the municipal nursery. These plants are the first ones to be used in areas under construction.

\subsubsection{Biodiversity}

Many animal species live in Frédéric-Back Park and some are considered rare, vulnerable or threatened. To help them survive and to enhance biodiversity, park improvements include specially designed habitats such as bird houses and perches, pollinator, monarch butterfly and coyote corridors, a marsh for amphibians and aquatic birds with nesting areas, and so forth. When wildlife is affected by design elements, the design is modified. For instance, decals will be added on glass railings to avoid bird collision, bird injuries are prevented by modifying the ignition of the LFG flare, etc.

\subsubsection{Ecological storm water management}

In Frédéric-Back Park, rainwater is controlled and directed along the surface to keep it from seeping into subsurface waste materials and generating leachate. The hilly topography of each watershed (there are 3 on the site) quickly channels water to ditches leading downhill to a retention basin. This technique is more environmentally friendly and less expensive to build and repair than standard techniques. It also resists better to soil subsidence, does not need protection from freezing, and nurtures biodiversity. Ultimately, the retention basins for the south and west watersheds will be enlarged and naturalized to create interesting wildlife habitats; the north watershed will have a filtering first flood marsh where water will be cleaned before being directed to the lake, where activities such as canoeing, pedal boats or kayaking are considered.

\subsubsection{Zero waste promotion}

The park is built on 40 million tonnes of waste that was landfilled over more than 30 years. The vastness of this park really marks the imagination and therefore helps bring citizens to realize how much waste is produced by the human kind. This very special environment creates awareness to help promote the zero-waste concept. Also note that to create even more awareness it is planned not to install waste receptacles in the Centre. Instead, people will be asked to carry any waste they produce onsite to the perimeters of the park (the Crown) where the specific waste receptacles are installed. To incite users to dispose of their waste in this manner and to explain zero-waste-concept, educational panels will be strategically installed where users are most likely to produce waste, for example, in picnic areas.

\section{CONCLUSIONS}

The City of Montreal is in the process of converting a large landfill into the Frédéric-Back Park for the benefit of



FIGURE 11: Ash trees attacked by the emerald ash borer being used for furniture. 
the population. This process was initiated 35 years ago and should be completed by 2026. It is the result of a close collaboration between the Department of Parks and the Department of Environment of the City of Montreal in order to meet the needs of both past and future functions of this site. Montrealers already enjoy the areas of the park open to the public every season of the year to engage in pleasant recreational activities or take part in festive events at this stunning venue with unique views of Montreal.

The site development has been supported by seven different administrations since the beginning of the project because it represents a win-win goal for the best ambassadors of the park, the citizens themselves, and the other stakeholders.

Many presentations regarding this project have been made to local, national and international forums over the last 25 years. Also, more than 40 papers have been published in general and specialized journals within Canada and internationally. Every year, the park receives 80 to 100 requests for technical visits from national and international delegations. Moreover it received many prizes and recognition, among others a Merit prize, in 2004, from The International Award for Liveable Communities and a Gold Medal Award from Expo Shanghai 2010 - Environmentally Sustainable Projects.

Frédéric-Back Park is Quebec's most ambitious environmental rehabilitation project in an urban setting to date. It's an ongoing experimental lab based on creativity, innovation and know-how in environmental technology. This project helps position Montreal as an innovating city and offers municipal residents an original park they can be great pride of!

\section{ACKNOWLEDGEMENTS}

The authors wish to thank all the people that have worked or will work to rehabilitate Montreal's landfill and to build Frédéric-Back Park.

\section{REFERENCES}

Ayodele T. R., Alao, M. A., Ogunjuyigbe, A. S. O., 2020. Effect of Collection Efficiency and Oxidation Factor on Greenhouse Gas Emission and Life Cycle Cost of Landfill Distributed Energy Generation. Sustain. Cities Soc., vol 52, 101821.

Bériault, A., Simard, G., 1978. Carte hydrogéologique de l'lle de Montréal et des îles Perrot et Bizard. Ministère des richesses naturelles du Québec, Direction générale des eaux, Service des eaux souterraines.
De la Cruz, F. B., Green, R. B., Hater, G. R., Chanton, J. P., Thoma, E. D., Harvey, T. A., Barlaz, M. A., 2016. Comparison of Field Measurements to Methane Emissions Models at a New Landfill. Environ. Sci. Technol. vol. 50, 9432-944.

Ethnoscop, 2013. Complexe environnemental de Saint-Michel - Étude archéologique et historique. Rapport d'étude produit pour le compte de la Ville de Montréal.

Fécil, B., Héroux, M. et Guy, C., 2003. Development of a Method for the Measurement of Net Methane emissions from MSW Landfills. Sardinia 2003 - Ninth International Waste Management and Landfill Symposium, Sardinia, Italy.

Franzidis, J. P., Héroux, M., Nastev, M., \& Guy, C. 2008. Lateral Migration and Offsite Surface Emission of Landfill Gas at City of Montreal Landfill Site. Waste Manage. Res., vol. 26, 121-131.

Héroux, M., Guy, C., Millette, D. 2010. A Statistical Model for Landfill Surface Emissions. J. Air Waste Manage. Assoc., Vol. 60 (2), 219228.

Héroux, M. 2008. Développement d’outils de gestion des biogaz produits par les lieux d'enfouissement sanitaire. PhD dissertation, Département de génie minéral, Polytechnique Montreal, Montreal, Quebec, Canada.

Héroux, M., 2000. Environmental Monitoring at the City of Montreal Sanitary Landfill Site. International Solid Waste Association World Congress, Paris, France.

Héroux, M., Turcotte, L., 1997. Control and Monitoring of Landfill Gas Underground Migration at the City of Montreal Sanitary Landfill Site. Air \& Waste Management Association's 90th Annual Meeting \& Exhibition, Toronto, Canada.

Héroux, M. Dubois, J., 1994. Monitoring Wells for the Migration of Landfill Gas and Leachate on a Sanitary Landfill Site. 17th International Madison Waste Conference, Madison, Wisconsin, USA.

Lagos, D. A., Héroux, M., Gosselin, R., and Cabral, A. 2017. Optimization of a landfill gas collection shutdown based on an adapted first-order decay model. Waste Manage., vol. 63, 238-245.

Lee, U., Han, J., Wang, M., 2017. Evaluation of Landfill Gas Emissions from Municipal Solid Waste Landfills for the Life-Cycle Analysis of Waste-to-Energy Pathways. J. Clean. Prod., vol. 166, 335-342.

Nastev, M., Lefebvre, R., Therrien, R., \& Gelinas, P., 2003. Numerical Modeling of Lateral Landfill Gas Migration. J. Solid Waste Technol. Manage, 29 (4), 265-276.

Nastev, M., 1998. Modeling Landfill Gas Generation and Migration in Sanitary Landfills and Geological Formations. PhD dissertation, Laval University, Quebec, Canada.

Spokas, K., Bogner, J., Chanton, J. P., Morcet, M., Aran, C., Graff, C., Moreau-Le Golvan, Y., Hebe, I., 2006. Methane Mass Balance at Three Landfill Sites: What is the Efficiency of Capture by Gas Collection Systems? Waste Manage., vol. 26, 516-525.

Sun, W., Wang, X., DeCarolis, J. F., Barlaz, M. A., 2019. Evaluation of Optimal Model Parameters for Prediction of Methane Generation from Selected U.S. Landfills. Waste Manage., vol. 91, 120-127.

Tremblay, M., Héroux, M. et Nastev, M., 2001. Monitoring of Three Instrumented Final Covers at the City of Montreal's Landfill Site. Sardinia 2001 - Eight International Waste Management and Landfill Symposium, Sardinia, Italy.

Tremblay, M., Héroux, M., 1999. Le choix d'un concept de recouvrement final pour le lieu d'enfouissement sanitaire de la Ville de Montréal. 52e conférence canadienne de géotechnique, Société canadienne de géotechnique, Régina, Saskatchewan, Canada.

Wang, Y., Levis, J. W., Barlaz, M. A., 2020. An Assessment of the Dynamic Global Warming Impact Associated with Long-Term Emissions from Landfills. Environ. Sci. Technol., vol. 54, 1304-1313. 